\title{
OSTEOCHONDRITIS DISSECANS OF THE ANKLE
}

\author{
A 20-YEAR FOLLOW-UP STUDY
}

MATS BAUER, KJELL JONSSON, BJARNE LINDÉN

From the Departments of Orthopaedic Surgery and Diagnostic Radiology, Malmö General Hospital, Sweden

\begin{abstract}
Thirty patients with osteochondritis dissecans of the ankle have been followed up for an average of 21 years. The histories and radiographs were revięwed, and it was found that most patients had only minor radiographic changes and symptoms. Two patients had developed osteoarthritis but in only one was this severe. Osteochondritis dissecans in the ankle thus seems to differ from the same lesion in the knee where late osteoarthritis often occurs. Two lesions were located on the joint surface of the distal tibia, a site not previously reported.
\end{abstract}

The natural history of osteochondritis dissecans of the ankle has not been widely studied, although the results of its treatment have been extensively reported (Rödén, Tillegård and Unander-Scharin 1953-54; Berndt and Harty 1959; Rosenberg 1965; Mukherjee and Young 1973; Rodegerdts 1975; McCullough and Venugopal 1979; Lindholm, Österman and Vankka 1980; Canale and Belding 1980; O'Farrell and Costello 1982; Rynn, Fazekas and Hecker 1983; Anderson and Lyne 1984; Flick and Gould 1985). Whether the natural history of osteochondritis of the ankle differs from that of the same lesion in the femoral condyles is not known. The purpose of the present study was to investigate the natural course and long-term prognosis of the disease in the ankle.

\section{PATIENTS AND METHODS}

From 1954 to 1974 the population of Malmö increased from 192000 to 250000 , during which time there was only one hospital in the city with surgical facilities. In 1985 the files of the Department of Diagnostic Radiology of that hospital were searched for patients with osteochondritis dissecans of the ankle who had been seen between 1954 and 1974. All radiographs from that period had been preserved, and the films of 82 patients with osteochondritis dissecans of the talus were found. Of these, 30 patients were still living in the city and were

M. Bauer, MD, Department of Orthopaedic Surgery

K. Jonsson, Department of Diagnostic Radiology

University of Lund, Malmö General Hospital, S-214 01 Malmö, Sweden.

B. Lindén, MD, Department of Orthopaedic Surgery Eksjö-Nässjö Hospital, S-575 00 Eksjö, Sweden.

Requests for reprints should be sent to $\mathrm{Mr} \mathrm{M}$. Bauer.

(C) 1987 British Editorial Society of Bone and Joint Surgery $0301-620 \mathrm{X} / 87 / 1003 \$ 2.00$ included in the study; the remaining 52 patients had either moved from the area and were not available for follow-up or had died.

The 30 patients were seen by the authors on average 21 years (range 11 to 31 years) after the initial diagnosis had been made. All previous details of their lesions were recorded and classified into one of four groups, using the criteria of McCullough and Venugopal (1979) for evaluating subjective complaints. The need for a walking stick or an analgesic was also recorded. Any change of physical activity which could, with any certainty, be ascribed to the lesion was noted. The range of movement of the ankle was measured; any restriction of dorsiflexion, plantarflexion, pronation or supination as compared with the other ankle was considered abnormal. Maximal dorsiflexion while weight-bearing also was recorded (Lindsjö 1981).

During the follow-up examination, three standard radiographic projections - anteroposterior, lateral and the mortise view - were taken of both ankles. These radiographs were then compared with those taken at the time of the initial diagnosis; the extent of the lesions in the anteroposterior projection was measured on both sets of radiographs and estimated as a percentage of the joint surface. Osteoarthritis was diagnosed if there had been any narrowing of the joint space, either localised or generalised. Bone sclerosis or cyst formation also was noted. Osteophytosis alone was not regarded as a sign of osteoarthritis.

The patients included in the study are presented in Table I. Six of 31 joints in the 30 patients had been treated by operation; in four, only an exploratory arthrotomy had been performed. One patient, diagnosed when a child, had had a subtalar arthrodesis because of post-encephalitic paresis. In one adult patient a talocrural arthrodesis had been performed because of pain. 


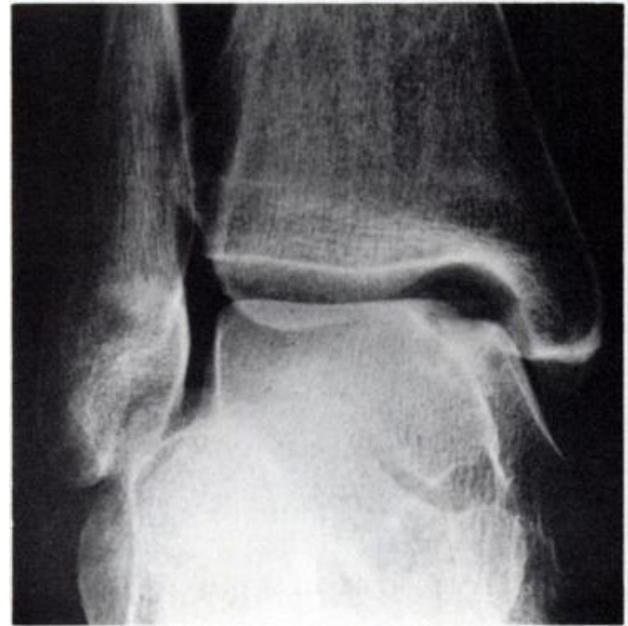

Fig. 1

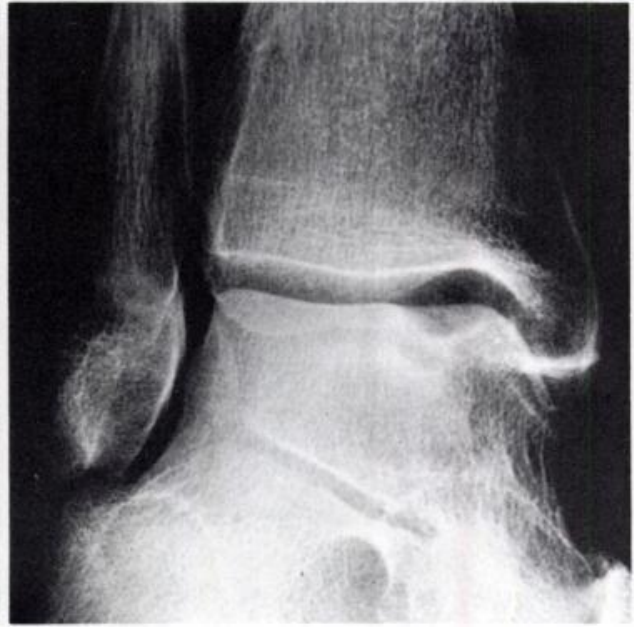

Fig. 2

Osteochondritis dissecans in the medial part of the talus. Figure 1 - Initial appearance in a woman aged 50 Figure 2 - Appearance at follow-up 17 years later.

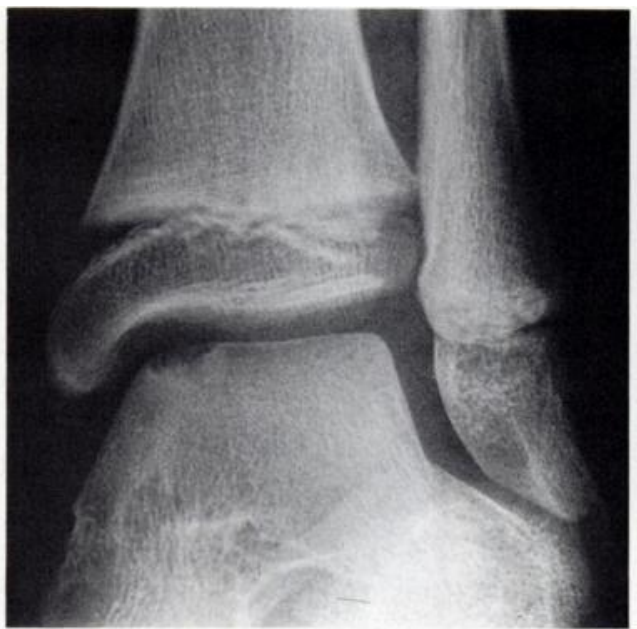

Fig. 3

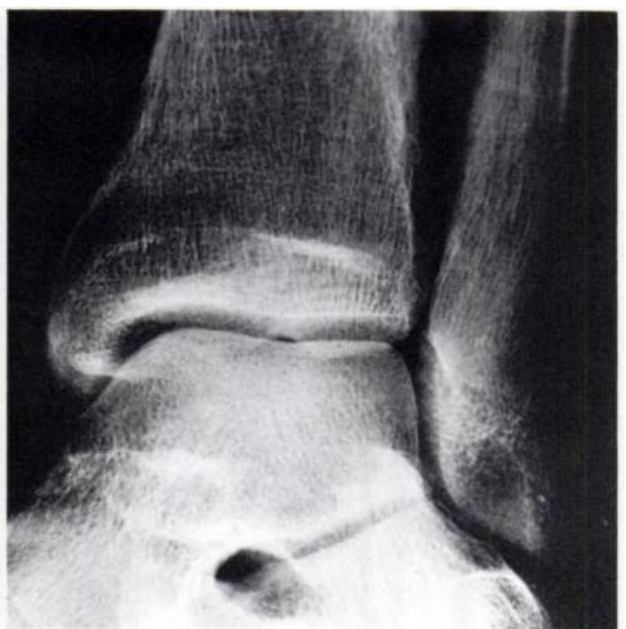

Fig. 4

Lesion in the medial part of talus. Figure 3 - Initial appearance in a 10-year-old boy. Figure 4 - Appearance at follow-up 26 years later.

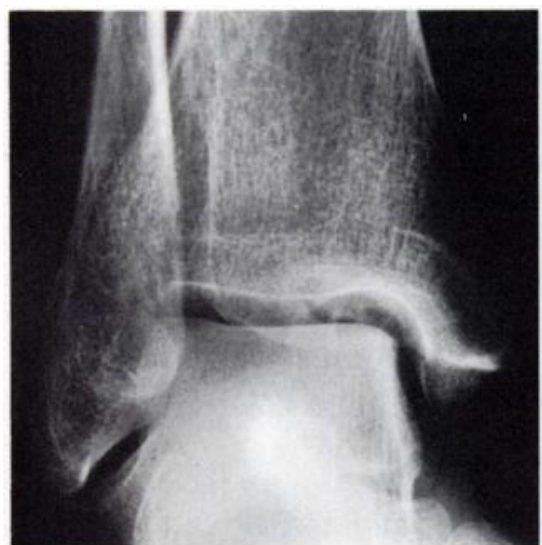

Fig. 5

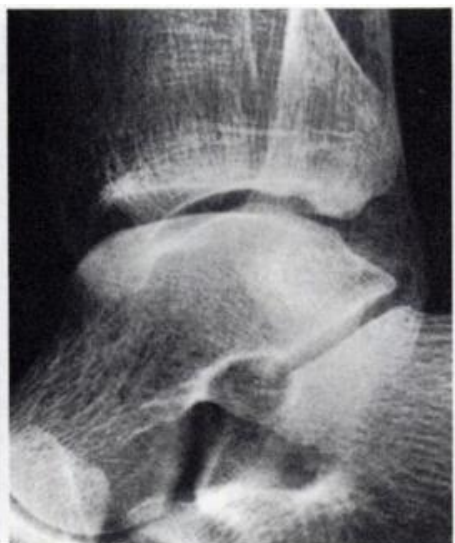

Fig. 6

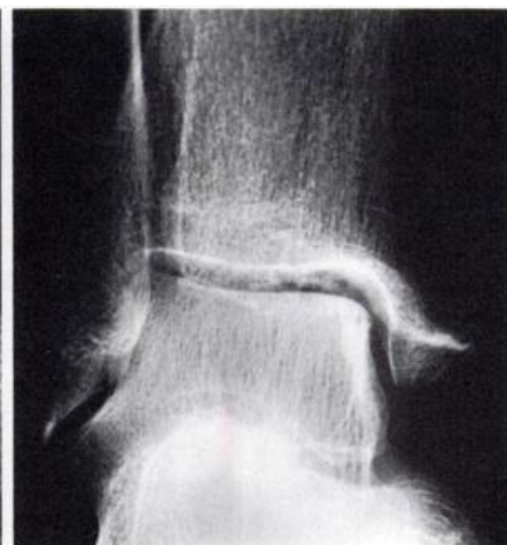

Fig. 7

Lesion in the distal end of tibia. Figures 5 and 6 - Anteroposterior and lateral views of the ankle of a woman aged 51. Figure 7 Anteroposterior view at follow-up 17 years later. 
Table I. Patients affected by osteochondritis dissecans of the talus or tibia

\begin{tabular}{|c|c|c|c|c|c|c|c|}
\hline \multirow{3}{*}{$\begin{array}{l}\text { Number of } \\
\text { patients }\end{array}$} & \multicolumn{4}{|c|}{ Site of lesion } & \multirow{3}{*}{$\begin{array}{l}\text { Average age at } \\
\text { diagnosis } \\
\text { (years) }\end{array}$} & \multirow{3}{*}{$\begin{array}{l}\text { Average age at } \\
\text { follow-up } \\
\text { (years) }\end{array}$} & \multirow{3}{*}{$\begin{array}{l}\text { Follow-up } \\
\text { (years) }\end{array}$} \\
\hline & \multicolumn{3}{|l|}{ Talus } & \multirow[b]{2}{*}{ Tibia } & & & \\
\hline & Lateral & Medial & Central & & & & \\
\hline Adults 25 & 2 & 22 & 0 & 2 & $42.3(21$ to 83$)$ & 59.3 (34 to 94$)$ & 20 (11 to 31$)$ \\
\hline Children 5 & 0 & 3 & 2 & 0 & $10.4(7$ to 12$)$ & 32.8 (27 to 34$)$ & 22 (15 to 27$)$ \\
\hline
\end{tabular}

One further joint had been treated by immobilisation in plaster immediately after diagnosis in 1966 in an attempt to heal the lesion.

\section{RESULTS}

All the lesions of osteochondritis dissecans initially diagnosed when the patient was an adult had the same radiographic appearance at follow-up (Figs 1 and 2). When the first and latest radiographs were compared there were only small differences in the percentage of the joint area affected (from $-4 \%$ to $+5 \%$ ).

Radiographic signs of osteoarthritis were found in only two ankles at follow-up; in one ankle these changes were minimal and in one severe. Both patients were adults when the diagnosis was made; the patient with mild osteoarthritis had also sustained a trimalleolar fracture of the ankle 15 years before the follow-up examination, and this injury may have contributed to the development of the arthritic changes. The patient who developed severe osteoarthritis had moderate changes at the first examination.

One patient had symptomatic lesions in both tali. In another six patients, lesions were also detected in the contralateral ankle at follow-up, although these joints were asymptomatic and were thus not included in this study.

None of the five patients diagnosed when children had developed any sign of osteoarthritis. Four of these lesions had healed with no remaining sign of osteochondritis dissecans (Figs 3 and 4); in one patient the lesion had not changed.

In the assessment of subjective complaints, 13 of the 25 adult patients (with 26 lesions) were graded excellent, seven good, six fair and none as poor. Of the five diagnosed when they were children, four were graded excellent and one good. Only two of the adults had reduced their physical activity because of the lesions, and at follow-up each used a walking stick; one had severe osteoarthritis and the other had had a talocrural arthrodesis in an attempt to relieve pain.

In the adult patients, apart from the one treated by arthrodesis, 19 ankles had a normal range of flexion and extension as well as pronation and supination. In six these ranges were slightly reduced $\left(<10^{\circ}\right)$ while four had an increased range of movement when compared with the uninjured side. The children, except the one treated by subtalar arthrodesis, all had a normal range of movement.

In two patients the lesion was found on the joint surface of the distal tibia (Figs 5 to 7); both patients had been diagnosed when adults. Apart from their site, these lesions were no different from those of the other patients.

\section{DISCUSSION}

Primary osteoarthritis of the ankle is extremely rare (Funk 1976; Resnick and Niwayama 1981) since, even after fractures, movement seems not to be impeded by minor irregularities of the joint surfaces (Bauer, Jonsson and Nilsson 1985).

There has been some discussion as to whether osteochondritis dissecans of the ankle leads to osteoarthritis (Rodegerdts 1975; McCullough and Venugopal 1979; Canale and Belding 1980; Flick and Gould 1985). However, in previous reports either the period of followup has been relatively short (Mukherjee and Young 1973; Flick and Gould 1985) or the diagnosis of osteoarthritis has not been based on radiographic findings (Rödén et al. 1953-54).

The present long-term study suggests that in children the lesion heals and disappears. In this respect it seems to behave like some of the lesions found in the femoral condyles of children. In adults, however, osteochondritis dissecans of the knee often leads to osteoarthritis (Lindén 1976), although osteochondritis dissecans of the ankle seldom does.

There has been some debate about the merits of either operative or conservative treatment of these ankle lesions (Rödén et al. 1953-54; Berndt and Harty 1959; Rosenberg 1965; Mukherjee and Young 1973; Rodegerdts 1975; Funk 1976; McCullough and Venugopal 1979; Canale and Belding 1980; O'Farrell and Costello 1982). Our findings seem to support conservative treatment since the lesions appear to remain unchanged over the years and cause little discomfort; in this respect our findings accord with those of Lindholm et al. (1980) and O'Farrell and Costello (1982).

The prognosis for medial lesions of the talus has been said to differ from that of lateral lesions (Rödén et al. 1953-54) but, in the present series, lateral lesions were so few that no conclusions could be drawn.

In rare cases the lesions can also be found in the central part of the talus (Mukherjee and Young 1973; 
Rodegerdts 1975; Canale and Belding 1980), and in our study we found osteochondritis dissecans or a similar lesion on the joint surface of the distal tibia in two patients. As far as we can ascertain this is the first time that this has been described but, clinically and radiologically, the lesions in these two patients did not differ from those found in the talus.

The prevalence of osteochondritis dissecans in the condyles of the femur has been estimated to be 0.6 per thousand for men and 0.3 per thousand for women under the age of 50 years (Lindén 1976), and similar attempts to estimate the prevalence of osteochondritis dissecans in the ankle have been made (Lindholm et al. 1980; O'Farrell and Costello 1982). In this series from one city hospital serving a stable population, the prevalence was calculated to be 0.002 per thousand, regardless of sex and age.

Although the aim of the present study was not to discuss the aetiology of osteochondritis dissecans of the talus, some comments may be made. The lesions in children were indistinguishable from those found in adults, and the fact that four of the lesions in children healed suggests that they may have been variants in the ossification of the talus. The high incidence of bilateral lesions (in 7 of 30 patients) suggests that trauma is not the only cause and that some local factor, perhaps circulatory, also is present.

This study was supported by grants from the Herman Järnhardt Foundation.

\section{REFERENCES}

Anderson DV, Lyne ED. Osteochondritis dissecans in the talus: case report on two family members. J Pediatr Orthop 1984:4:356-7.

Bauer M, Jonsson K, Nilsson B. Thirty-year follow-up of ankle fractures. Acta Orthop Scand 1985:56:103-6.
Berndt AL, Harty M. Transchondral fractures (osteochondritis dissecans) of the talus. J Bone Joint Surg [Am] 1959: 41-A :988-1020.

Canale ST, Belding RH. Osteochondral lesions of the talus. J Bune Joint Surg $[\mathrm{Am}]$ 1980;62-A:97-102.

Cedell C-A. Supination-outward rotation injuries of the ankle : a clinical and roentgenological study with special reference to the operative treatment. Acta Orthop Scand 1967; Suppl 110.

Flick AB, Gould N. Osteochondritis dissecans of the talus (transchondral fractures of the talus): review of the literature and new surgical approach for medial dome lesions. Foot Ankle 1985:5:165-85.

Funk FJ Jr. Osteoarthritis of the foot and ankle. American Academy of Orthopaedic Surgeons symposium on osteoarthritis. St Louis: CV Mosby, 1976:287-301.

Lindén B. Osteochondritis dissecans of the femoral condyles: a longterm follow-up study. J Bone Joint Surg [Am] 1977:59-A:769-76.

Lindén B. The incidence of osteochondritis dissecans in the condyles of the femur. Acta Orthop Scand 1976;47:664-7.

Lindholm TS, Österman K, Vankka E. Osteochondritis dissecans of elbow, ankle and hip: a comparison survey. Clin Orthop 1980:148:245-53.

Lindsjö U. Operative treatment of ankle fractures. Acta Orthop Scand 1981:52:Suppl 189

McCullough CJ, Venugopal V. Osteochondritis dissecans of the talus: the natural history. Clin Orthop 1979;144:264-8.

Mukherjee SK, Young AB. Dome fracture of the talus: a report of ten cases. J Bone Joint Surg [Br] 1973:55-B:319-26.

O'Farrell TA, Costello BG. Osteochondritis dissecans of the talus: the late results of surgical treatment. J Bone Joint Surg [Br] 1982; 64-B:494-7.

Resnick D, Niwayama G. Degenerative disease of extraspinal locations. In: Resnick D, Niwayama G, eds. Diagnosis of bone and joint disorders with emphasis on articular abnormalities. Vol. 2. Philadelphia etc: WB Saunders, 1981:1270-1351.

Rodegerdts U. Atiologie, Therapie und Prognose der Osteochondrosis dissecans der Talusrolle. Arch Orthop Trauma Surg 1975:83:45-55.

Rödén S, Tillegárd P, Unander-Scharin L. Osteochondritis dissecans and similar lesions of the talus: report of fifty-five cases with special reference to etiology and treatment. Acta Orthop Scand $1953-54 ; 23: 51-66$.

Rosenberg NJ. Fractures of the talar dome. $J$ Bone Joint Surg [Am] $1965: 47-A: 1279$.

Rynn M, Fazekas EA, Hecker RL. Osteochondral lesions of the talus. $J$ Foot Surg 1983:22:155-8. 